\title{
Study on the New Pathway of Ecological Poverty Alleviation an Forest Health Industry Integrated Development
}

\author{
Weitao Xu ${ }^{1}$, Heding Shen ${ }^{1}$, Liqiang Zhang ${ }^{1}$, Laicheng Yang ${ }^{2}$, , An Mao, , , Yifu Yuan ${ }^{2, ~ * ~}$ \\ ${ }^{1}$ Planning and Design Institute of Forest Products Industry of National Forestry and Grassland Administration, Beijing, China \\ ${ }^{2}$ College of Forestry, Shandong Agricultural University, Taian, China
}

\section{Email address:}

mjgbw_001@163.com (Weitao Xu), shd1965@sina.com (Heding Shen),32712361@qq.com (Liqiang Zhang),

yanglcc@126.com (Laicheng Yang), dannymaoan@126.com (An Mao),yuanyf16@163.com (Yifu Yuan)

${ }^{*}$ Corresponding author

\section{To cite this article:}

Weitao Xu, Heding Shen, Liqiang Zhang, Laicheng Yang, An Mao, Yifu Yuan. Study on the New Pathway of Ecological Poverty Alleviation an Forest Health Industry Integrated Development. American Journal of Environmental Science and Engineering.

Vol. 4, No. 4, 2020, pp. 70-74. doi: 10.11648/j.ajese.20200404.14

Received: December 4, 2020; Accepted: December 14, 2020; Published: December 22, 2020

\begin{abstract}
Forest has the function of nourishing body and mind, promoting health, enhancing human immunity, which is of great significance to improve health index. Forest health care can give full play to the advantages of forest landscape, environment, space and culture, and extend forest functions. It is a new industry integrating forestry, health services, tourism and leisure industry, and is a new trend of sustainable development of forestry. Ecological poverty alleviation is a kind of poverty alleviation mode which combines ecological protection with poverty alleviation and development. Through the implementation of major ecological engineering construction, increasing ecological compensation, vigorously developing ecological industry, and innovating ecological poverty alleviation methods, the support for poverty-stricken areas and the poor population should be strengthened, so as to achieve the poverty alleviation mode of coordinating poverty alleviation development and ecological protection, and promoting poverty alleviation and prosperity with sustainable development, and finally achieve the goal of poverty alleviation and ecological civilization construction Win. Forest health care is a new way of ecological poverty alleviation. Forest health care can give full play to the resource advantages of mountain areas and drive mountain farmers to get rid of poverty and become rich. It is an effective way of forestry reform, forestry innovation and forestry development, and an inevitable trend to promote green prosperity and poverty alleviation. Based on the model of forest health care, this paper deeply analyzes the development status of forest health industry, discusses the measures to optimize the path of ecological poverty alleviation, and puts forward suggestions on the long-term development mechanism of organic combination of forest health industry development and ecological poverty alleviation work.
\end{abstract}

Keywords: Forest Health Care, Ecological Poverty Alleviation, Sustainable Development, Health

\section{Introduction}

Forest health care is a series of activities beneficial to human physical and mental health, such as forest landscape, environment, food, ecological culture, and so on, equipped with corresponding health care and recuperation service facilities, to carry out a series of activities beneficial to human physical and mental health, such as forest recreation, vacation, recuperation, health care, sports and so on. It can be understood as forest medical health care and forest health experience industry with Chinese characteristics. As a comprehensive service function of exploring the forest, forest health care plays a positive role in meeting the needs of the public for deep forest experience, improving people's quality of life and improving public health $[1,2]$.

Forest has the function of nourishing body and mind, promoting health, enhancing human immunity, which is of great significance to improve health index. Forest health care can give full play to the advantages of forest landscape, environment, space and culture, and extend forest functions. It is a new industry integrating forestry, health services, tourism and leisure industry, and is a new trend of sustainable development of forestry. Specifically, forest health care has 
the following advantages: (1) it can effectively alleviate obesity, hypertension, hyperlipidemia and other health problems and some mental diseases, which is the first choice for urban residents who have been in sub-health state for a long time to improve their quality of life. (2) At the same time, the development of forest health can optimize the industrial structure, improve the business model and promote the development of new economy. (3) Forest health care can deeply integrate traditional tourism with industry forms such as recuperation, culture, sports, pension, etc., realize cluster, base and scale rapidly, cultivate multi-functional industrial consortia and form new pillar industries. In recent years, with the growth of people's health care needs, people began to consider forest health care as the first choice for leisure vacation. The rich forest resources and environmental advantages have become an important attraction for tourists. The large-scale supporting facilities and services of forest health care can attract more forest leisure vacation and medical care projects to settle in, which is conducive to further building a perfect forest health care system $[3,4]$.

\section{The Development of Forest Health Industry in Foreign Countries}

Forest health care originated in Germany. In the 1840s, Germany established the world's first forest bath base, forming the initial concept of forest health. From 1980 to 2000, Japan and South Korea also began to actively develop the forest industry. The forest health industry of the two countries developed rapidly. At the same time, a large number of managers with professional quality were trained and forest recuperation bases were established. At present, there are about 350 forest convalescent bases in Germany, and there are more than 60 natural therapy convalescent places, accounting for about $16 \%$ of all the convalescent places. In this type of sanatorium, forest recuperation plays an important role.

Japan has the world's most advanced scientific forest health care efficiency measurement technology, and its research level in forest recuperation theory and practice is ahead of the world. Japan has established a complete forest Recuperation Base certification system and forest recuperator assessment system, and set up a fixed forest recuperation course. At present, more than 60 forest recuperation bases have been certified. The forest recuperation management is standardized and effective, and it is highly recognized in Japanese society [5, 6].

At present, South Korea has relatively perfect forest Recuperation Base standard and corresponding forest recuperation service personnel level training and qualification certification system.

Generally speaking, Germany, Japan and South Korea are countries with relatively mature development of health care industry. Their health care system has formed a fairly complete system and a large scale, which is worth learning and learning from.

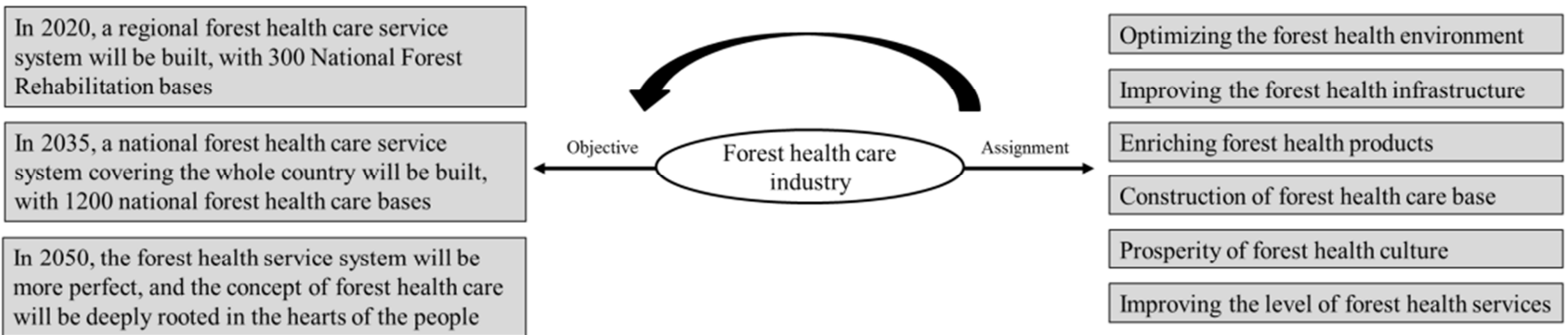

Figure 1. Objectives and assignments of Chinese forest health care industry.

\section{Development Status of Forest Health Industry in China}

As an industry, the development of forest health care in China has just begun, but there are several objectives and assignments (Figure 1). In 2012, Beijing took the lead in introducing the concept of forest health care and began to explore the construction of forest recuperation demonstration area. Subsequently, Hunan, Sichuan, Guizhou, Shaanxi and other provinces began to pay attention to the new business form of forest health care, which promoted the industrialization development of forest health care [7].

The experimental forest farm of Hunan Academy of Forestry Sciences took the lead in establishing Hunan forestry health care center in 2012 to create a new brand of green health industry. In 2016, Hunan formulated and issued the first provincial forest health care plan. In 2015, Sichuan formulated the development opinions, base construction standards, base evaluation methods and the 13th five year plan for the development of forest health care, and determined more than 60 forest health care bases. In June 2017, the Forestry Department of Sichuan Province launched a forest health campaign to encourage citizens to experience forest health [8]. Guizhou has held a series of international forums on ecological civilization in Guiyang by seizing the opportunity of the construction of the national ecological civilization experimental zone. One of the sub forums specially set up a special seminar on forest health and conservation to explore how to use the advantages of forest resources to create a unique new mode of green economy. Guizhou has released the first batch of 12 provincial-level forest health care pilot bases and established local standards for forest health and conservation bases. In September 2017, Shaanxi Province 
established the Forest Conservation Alliance of Shaanxi Provincial Forest Culture Association to coordinate the cooperation of relevant enterprises and institutions, social groups and individuals, build a forest health industry platform, spread forest health culture, and increase the development pace of forest health industry in Shaanxi Province.

At the end of 2015, the forest medicine and Health Promotion Association of China Forestry Industry Federation launched the selection of pilot construction units of national forest health care base. 233 pilot construction units of national forest health care base, three pilot construction counties of national forest health base and one pilot construction area of National Forest Health care base have been determined in three batches. In November 2017, the China Forest Farm Association established the forest health and conservation professional committee, which is committed to strengthening scientific research, education and training in the field of forest health, as well as exchanges and cooperation at home and abroad, so as to help build a beautiful and healthy China. At the same time, some universities and scientific research institutes have begun to carry out scientific and technological research and personnel training of forest health care [9].

In recent years, Hebei, Beijing, Shaanxi, Heilongjiang and other places have carried out beneficial exploration on the construction of forest health care, and started to set up forest health care base pilot, and actively promote the new industrial economy centered on forest health care. As an emerging industry, forest health care in China is still in its infancy and has great development potential.

\section{Ecological Poverty Alleviation Based on Forest Health Care Model}

Ecological poverty alleviation is a kind of poverty alleviation mode which combines ecological protection with poverty alleviation and development. Through the implementation of major ecological engineering construction, increasing ecological compensation, vigorously developing ecological industry, and innovating ecological poverty alleviation methods, the support for poverty-stricken areas and the poor population should be strengthened, so as to achieve the poverty alleviation mode of coordinating poverty alleviation development and ecological protection, and promoting poverty alleviation and prosperity with sustainable development, and finally achieve the goal of poverty alleviation and ecological civilization construction win [10].

Forest health is a new way of ecological poverty alleviation. Forest health care can give full play to the resource advantages of mountain areas and drive mountain farmers to get rid of poverty and become rich. It is an effective way of forestry reform, forestry innovation and forestry development. It is an inevitable trend to promote green prosperity and poverty alleviation, and has high social value.

From the state to the local, it is necessary to establish an ecological security and healthy society. On the basis of protecting the existing forest land resources and maintaining the national ecological security, we should implement the spirit of the relevant national documents, promote the side supply reform, meet the needs of the people in a well-off society with new industrial formats, improve the level of public resources and services, promote the transformation and upgrading of economic structure, and promote the integrated development of industries Based on ecological construction and ecological protection, we should take forestry departments and forest resources as the core, realize multi sectoral cooperation in forestry, sports, urban construction and traditional Chinese medicine, promote forestry industry, tourism and leisure, medical health care, traditional Chinese medicine health care, sports fitness, rural tourism and small town construction, so as to promote all-round development. It is beneficial to give full play to the important role of forestry in ecological poverty alleviation by giving full play to the multiple functions of forest, accelerating the transformation of forestry development mode and stimulating forestry productivity. On the premise of protecting ecological environment, we should make rational use of forest resources, and change the development mode from resource acquisition to comprehensive utilization of forest resources. Taking into account the three major benefits of ecology, economy and society, we should deepen the reform of forest property rights, promote the transformation and upgrading of forestry, innovate and build a new format of forest health care, and promote economic development. We should promote the increment of resources and increase the employment of employees, obtain considerable economic benefits without destroying the forest resources, transform the ecological advantages into development advantages and economic advantages, and effectively solve the livelihood problems of forest farmers and forestry workers [11].

In recent years, China's forestry industry has developed rapidly, continuously and healthily. The total output value of China's forestry industry increased from 409 billion yuan in 2001 to 6.4 trillion yuan in 2016, an increase of 13.5 times in 16 years. Forest, wetland and desertification account for $32 \%$, $6 \%$ and $18 \%$ of the total land area respectively. Mountainous area is the main battlefield of forestry construction. $69 \%$ of China's land area is mountainous area, and $56 \%$ of the population lives in mountainous area. Forest tourism not only attracts tourists to travel, its significance lies in driving farmers out of poverty and becoming rich through forest tourism and rural tourism [12]. The rapid development of forest tourism and ecological health care industry will become an important growth point of forestry and even national economy and an important force to promote health industry and targeted poverty alleviation [13].

\section{Development Mechanism of Organic Combination of Forest Health Care and Ecological Poverty Alleviation}

Taking forest health care as an example, the development of forestry industry and ecological poverty alleviation can be organically combined. The deep integration of forest health 
care and targeted poverty alleviation, the coordinated promotion and long-term development mechanism of forestry industry development and ecological poverty alleviation work are discussed. On the basis of in-depth analysis of the development status of forest health care industry and the poverty alleviation needs of forestry industry, we should give full play to the advantages of forest health care resources, optimize the path of ecological poverty alleviation, and promote the long-term development of the organic combination of the development of forest health care industry and ecological poverty alleviation work $[14,15]$.

(1) Forest specific biological resources can provide people with specific recuperation experience. At present, forest therapy can effectively solve obesity, hypertension, hyperlipidemia and other serious health problems and some mental diseases. Among many urban residents who have been in sub-health state for a long time, forest health care has been warmly welcomed. In addition, forest health care has irreplaceable resources and sustainable development mode. In the future, forest health care activities will become the first choice for people to improve their quality of life.

(2) Low carbon is not only a way to alleviate the problem of environmental degradation, but also an attitude towards life of modern people. The popularization of low-carbon economy has focused people's attention on how to create a healthy living environment. It is a part of low-carbon life to create a livable environment and carry out targeted health activities. At the same time, mountain and forest as the most ideal place for human health, also confirmed the ecological significance of forest health. This means that forest health care will become the development path of low-carbon economy and promote the organic combination of low-carbon and economic life.

(3) Forest health care model is not only a new attempt to transform the function of China's forest resources, but also a new starting point for the integration of China's health industry and tourism industry. At the same time, the development of forest health industry can improve and optimize the industrial structure, explore new business models, and then promote the formulation of new economic development strategies. Forest health care industry can connect traditional tourism with different industries, such as convalescent industry, cultural industry, sports industry, pension industry and so on. It can quickly realize clustering, base and scale, and cultivate a multi-functional industrial complex. Therefore, forest health care industry has the opportunity to become a new pillar industry of China's economy and create more benefits for the country and society.

(4) The weakening of traditional forest value and the strengthening of forest health value fully affirmed the status of forest health and provided new ideas for forestry transformation. At the same time, the social and economic benefits of forest health care directly determine its social and economic value. The development of forest health industry can give full play to the advantages of resource inspection and taxation in mountainous areas, and drive the farmers in mountainous areas to get rid of poverty and become rich. Therefore, forest health maintenance is an effective way for China's forestry reform, forestry innovation and forestry development, and is an inevitable trend to promote people's green income to become rich and poverty alleviation.

\section{Author Contributions}

The Manuscript was written through contributions of all authors. All authors have given approval to the final version of the manuscript.

\section{Conflicts of Interest}

The authors declare that they have no competing interests.

\section{Acknowledgements}

The research was supported by funding from research project "Study on the Mode of Forest Health Industry Promoting Ecological Poverty Alleviation" (Entrusted by Planning and Finance Department of State Forestry and Grassland Administration).

\section{References}

[1] Yang L. P, Sun H. J, Huang L. P, Gao Y. Q, Hu D. Y (2018) Research overview of forest health. Forest Inventory and Planning, 43 (2): 161-166.

[2] Chen X. L (2016) Research and development of forest health tourism. Journal of Heilongjiang Vocational Institute of Ecological Engineering, 29 (5): 25-27.

[3] Yan W (2016) Study on economic driving and environmental protection scheme of forest health industry. Journal of Green Science and Technology, 21: 101-102.

[4] Gou J. M, Yu X. M (2016) Speeding up the Science Development of Forest Health Industry in Sichuan. Sichuan Forestry Exploration and Design, 1: 15-20.

[5] Nan H. L, Wang X. P, Chen J. Q, Zhu J. G, Yang X. H, Wen Z. $\mathrm{Y}$ (2013) Forest therapy in Japan and its revelation. World Forestry Research, 26 (3): 74-78.

[6] Zhang Z. Q, Tan Y. M (2016) Japanese forest therapy base construction. Forest inventory and planning, 41 (5): 106-111.

[7] Tan Y. P, Zhang Z. Q (2017) Study on the planning and design of forest therapy base. Journal of Hunan University of Technology, 31 (1): 1-8.

[8] Liu C. W, Wang D. Y, Qiao Y. Q (2017) The exploration of forest wellness base construction. Forest Resources Management, 2: 93-96.

[9] Deng S. L (2016) Theoretic Research and Practices of Forest Health. World Forestry Research, 29 (6): 1-6. 
[10] Zhou C. X, Zhang F, Feng D, Ma H, Zhou D. L, Nan H. L (2015) Research on Promoting Public Health by Forest Therapy in Beijing. Journal of Beijing Forestry University (Social Sciences), 2: 13-16.

[11] Chen J, Shao J. A, Guo Y, Mou Y. J (2020) Status analysis of forest health research in China based on bibliometrics. Nanfang Forestry Science, 48 (1): 38-43.

[12] Qian Z. Q, Shen X. L (2020) Research on the Path of Ecological Culture and Forest Health Industry Integrated Development. China Forestry Economy, 5: 64-66.
[13] Guo M. H, Ji X. D (2014) An environment impact assessment method of wood construction based on life cycle assessment. Journal of Anhui Agricultural Sciences, 42 (36): 12965-12967.

[14] Hu J. H, Ji X. D, Dai Q. Guo M. H (2017) Environment impact of $\log$ house based on life cycle assessment. China Forestry Science and Technology, 2 (6): 133-138.

[15] Yang X. Y, Zhang S. C, Xu W (2019) Impact of zero energy buildings on medium-to-long term building energy consumption in China. Energy Policy, 129: 574-586. 